\title{
Detection of a polymorphic site of the porcine C8G gene and evaluation of association with haemolytic complement activity
}

\author{
Vo Anh Khoa Do ${ }^{1,2}$, Siriluck Ponsuksili³, Eduard Muráni', Huynh Thi Phuong Loan², \\ Ronald M. Brunner ${ }^{1}$ and Klaus Wimmers ${ }^{1}$ \\ 'Research Unit Molecular Biology, Leibniz Institute for Farm Animal Biology (FBN), Dummerstorf, Germany, ${ }^{2}$ Department \\ of Animal Sciences, College of Agriculture and Applied Biology, Cantho University, Cantho City, Vietnam, ${ }^{3}$ Research \\ Group Functional Genome Analysis, Leibniz Institute for Farm Animal Biology (FBN), Dummerstorf, Germany
}

\begin{abstract}
C8 is a component of the membrane attack complex (MAC) of the complement system, which causes lysis of the target cells. C8 consists of three subunits C8A, C8B, and C8G. This study focus on the porcine $C 8 G$ gene aiming to identify its CDNA sequence, to detect single nucleotide polymorphism (SNP), and to analyse its association with haemolytic complement activity in the classical ( $\mathrm{CH} 50)$ and the alternative (AH50) pathway. The C8G is 840 bp in length encoding 202 amino acids. The $C 8 G$ is similar ( $\geq 65 \%$ ) among mammalian species (pig, human, cattle, dog, and mouse) at both the CDNA and the protein level. One SNP was detected at nucleotide $423 \mathrm{C} \rightarrow \mathrm{T}$ (SNP c.423C $>$ T; codon 124GAC $\rightarrow$ GAT). The SNP does not segregate among the European commercial breeds German Landrace and Pietrain but in the Vietnamese autochthonous breed Muong Khuong (Vietnamese potbelly pig) and an experimental $F_{2}$ crossbreed population based on Duroc and Berlin Miniature Pig (DUMI). Haemolytic complement activity of animals of the DUMI populations obtained at about 6 , 14 and 16 weeks of age before and after vaccinations showed short-termed increments due to the immune stimulation and long-term increase due to aging. Family based association tests indicate effects of $\mathrm{C} 8 \mathrm{G}$ on $\mathrm{AH} 50$ and $\mathrm{CH} 50$ at 16 weeks of age immediately before PRRS vaccination (AH50_PRRSO, $P=0.087$; $C H 50 \_P R R S 0, P=0.027$ ). However, the results did not indicate a consistent effect of the respective alleles on haemolytic complement activity in the alternative and the classical pathway. The study provides weak evidence for the candidacy of the porcine $C 8 G$ for innate immune response and disease resistance in pigs.
\end{abstract}

Keywords: innate immunity, association, complement system

\section{Introduction}

The complement system is a part of the innate immune system, which directly contributes to killing of microbial cells. C8 is one of five components of the membrane attack complex (MAC) in the terminal pathway of the complement system. It is an oligomeric protein composed of three subunits C8A, C8B, and C8G that are derived from different genes (Plumb et al. 1999). The $C 8 A$ and $C 8 G$ subunits are bound covalently through a disulphide linkage, whereas the C8B is associated via weaker, non-covalent bonds (Alper et al. 1983). The genes encoding 
both $\mathrm{C} 8 \mathrm{~A}$ and $\mathrm{C} 8 \mathrm{~B}$ are homologous with the terminal complement components genes $\mathrm{C} 6, \mathrm{C}$, and $C 9$ while $C 8 G$ is distinct because it is a member of the lipocalins, a family of proteins that bind small hydrophobic ligands (Dewald et al. 1996, Schreck et al. 2000). Lipocalin proteins also play important roles in the innate immune system and the acute phase response to infection (Flo et al. 2004). This study focuses on the detection of polymorphisms of C8G and its association with haemolytic complement activity in pig.

\section{Materials and methods}

Samples of animals of the pig breeds Hampshire (HS, $n=1)$, Duroc ( $D R, n=1)$, German Landrace $(\mathrm{LR}, \mathrm{n}=30)$, Pietrain ( $\mathrm{PI}, \mathrm{n}=30)$, Berlin Miniature pig ( $\mathrm{BMP}, \mathrm{n}=1)$, and Muong Khuong $(M K, n=25)$ were used to sequence CDNA and to screen for SNPs.

Haemolytic complement activity in the classical (CH50) and alternative (AH50) pathway was determined in 417 animals of the $F_{2}$ DUMI resource population (Hardge et al. 1999) inoculated in succession with Mycoplasma hyopneumoniae (MH), Aujeszky Virus (ADV), and porcine reproductive and respiratory syndrome virus (PRRSV) vaccines at 6,14 and 16 weeks of age, respectively. $\mathrm{CH} 50$ and $\mathrm{AH} 50$ were measured before (MHO, ADV0, PRRSO) and after (day4: MH4, ADV4; day10: MH10, ADV10, PRRS10) vaccination (Wimmers et al. 1999, 2003).

DNA was extracted from ear or tail tissues whereas CDNA was synthesised from liver tissue, the major site of complement factor expression. Homologous CDNA fragments of C8G between various vertebrate species were aligned to retrieve available porcine sequences using the BLAST tool and the Trace Archive tool (http://blast.ncbi.nlm.nih.gov, National Center for Biotechnology Information, Bethesda, MD, USA). Overlapping expressed sequence tags (Sets) were found (GenBank acc. no. BP139629.1 and BP443148.1). Two pairs of primers ( $p$ C8G1 and $p$ C8G4) were assigned along the body of this sequence using the Primer3 tool (http://primer3.sourceforge.net, Rozen \& Skaletsky 2000) for comparative sequencing. In order to genotype C8G at the SNP site the primer pair $p$ C8G2.DNA was generated (Table 1).

Polymerase chain reaction (PCR) was performed in a total of $20 \mathrm{ml}$ containing $50 \mathrm{ng}$ of liver CDNA or $100 \mathrm{ng}$ of genomic DNA, $0.2 \mathrm{mM}$ of each primer (forward and reverse primer), $50 \mathrm{mM}$ of each dNTP, $0.5 \mathrm{U}$ of Taq polymerase and $1 \times \mathrm{PCR}$ buffer containing $1.5 \mathrm{mM}$ of $\mathrm{MgCl}_{2}$. Standard PCR thermal cycling program was set up with an initial denaturation step of $94^{\circ} \mathrm{C}$ for $4 \mathrm{~min}$, followed by $40 \mathrm{cycles}$ at $94^{\circ} \mathrm{C}$ for $30 \mathrm{~s}$, annealing at $58-62^{\circ} \mathrm{C}$ (up to each primer pair) for $30 \mathrm{~s}$, elongation at $72^{\circ} \mathrm{C}$ for $1 \mathrm{~min}$ and a final extension at $72^{\circ} \mathrm{C}$ for $5 \mathrm{~min}$. Three $\mu \mathrm{l}$ of PCR products were analysed on $1 \%$ agarose gel stained with ethidium bromide in $1 \times$ TAE buffer and electrophoresed to evaluate specificity and efficiency of the amplification. The remainder was purified by ethanol precipitation and used for sequencing or genotyping.

A SNP was detected by comparing sequenced CDNA fragments among porcine breeds and was confirmed by PCR-RFLP using restriction enzyme Psyl (GACN/NNGTC). After confirmation the PCR-RFLP was subsequently used for genotyping animals of the DUMI population.

In order to perform physical mapping of the candidate genes the INRA-University of Minnesota porcine 7000Rad Radiation Hybrid panel (IMpRH) containing 118 pig/hamster DNA hybrid clones (Yerle et al. 1998, Hawken et al. 1999) was employed using primer pair pC8G1. DNA (Table 1). Two-point linkage analysis was done using the IMpRH mapping tool available at the IMpRH Web Server (https://www-lgc.toulouse.inra.fr/pig/RH/IMpRH.htm, Milan et al. 2000). 
Table 1

Primer pairs used for experiment

\begin{tabular}{|c|c|c|c|}
\hline Primer pair & Sequence & Length, bp & Temp., ${ }^{\circ} \mathrm{C}$ \\
\hline \multirow[t]{2}{*}{$p C 8 G 1^{a}$} & up 5'-TCG TCC TGC TCT CTG TC TCC-3' & & \\
\hline & dw 3'-GCG TAC AGC TTC ACC GAC AG-5' & 505 (nt. 2-206) $^{d}$ & 60 \\
\hline \multirow[t]{2}{*}{$p C 8 G 4^{a}$} & up 5'-ACC TTC CGA AAG CTG GAT G-3' & & \\
\hline & dw 3'-TTG AGA CCG ACA GTG TTT AAT GA-5' & 500 (nt. 487-812) $^{d}$ & 60 \\
\hline \multirow[t]{2}{*}{ pC8G1.DNA ${ }^{b}$} & up 5'-CCT CTT GAC GCT GCT CCT-3' & & \\
\hline & dw 3'-GAG CCA CGT GCA GTG AAG T-5' & 296 (nt. 76-371) $^{e}$ & 58 \\
\hline \multirow[t]{2}{*}{$p C 8 G 2 . D N A^{c}$} & up 5'-CGG CAG CTC TTC AGA GAC A-3' & & \\
\hline & dw 3'-GGT ACA GGA TGG CAA AGC TC-5' & 192 (nt. 571-762)e $^{e}$ & 62 \\
\hline
\end{tabular}

$a, b, c$ for cDNA sequencing, IMpRH mapping, and genotyping, respectively, d,e according to GenBank acc. no. DQ333202 and AK233484, respectively

Association analysis was based on measurements of haemolytic complement activity in the classical and alternative pathway before and after vaccinations and pC8G genotypes obtained from DUMI $F_{2}$ animals. Family based association tests were performed using the FBAT package with the empirical variance option (»-e« option) and the null hypothesis stating no association in the presence of linkage (FBAT, http://www.biostat.harvard.edu/ fbat/ default.html, Laird et al. 2000). The quantitative association analyses were done in bi-allelic tests under the condition of an additive genetic model (Horvath et al. 2001). Residuals of the repeated measures mixed model (see below: factor genotype and its interaction were omitted to estimate residuals used in FBAT) were used as traits in the family based association test. Least square means (LSM) and standard errors (SE) for $\mathrm{CH} 50$ and AH50 data were estimated using the PROC MIXED procedure of SAS (SAS Institute Inc., Cary, NC, USA) and the repeated measures statement. The statistical model is given as follows:

$$
\begin{aligned}
y_{i j k l m n o}= & m+\text { sire }_{i}+\text { dam }_{j}+\text { parity }_{k}+\text { treatment }_{l}+\text { genotype }_{m}+\text { time }_{n}+\text { sex }_{o}+ \\
& \text { animal }_{i j k m o}+\left(\text { genotype } \times \text { time }_{m n}+\varepsilon_{i j k l m n o}\right.
\end{aligned}
$$

where $y_{i j k m n o}$ is the haemolytic complement activity $(\mathrm{CH} 50$ and $\mathrm{AH} 50), \mu$ is overall mean, sire $e_{i}$ is the fixed-effect of sire ( $i=1-3)$, dam $_{j}$ is the fixed-effect of dam ( $\left.j=1-11\right)$, parity ${ }_{k}$ is the fixed-effect of parity $(k=1-5)$, treatment, is the fixed-effect of treatment-vaccinated group/ unvaccinated group $(l=1-2)$, genotype ${ }_{m}$ is the fixed-effect of genotype $(m=1-3)$, time $e_{n}$ is the fixed-effect of time points of measurement prior and after vaccinations $(m=1-8)$, sex ${ }_{o}$ is the fixed-effect of sex $(o=1-2)$, animal $_{i j k m o}$ is the subject specified in the repeated statement, (genotype $\times$ time) ${ }_{m n}$ is the interaction between genotype and time point and $\varepsilon_{i j k m n o}$ is the residual error.

\section{Results and discussion}

The gene encoding the gamma chain of the eighth complement component of pig was comparatively sequenced and its genomic structure was deduced. The $p$ C8G CDNA sequence obtained consisted of $840 \mathrm{bp}$ including $51 \mathrm{bp}$ of the $5^{\prime}$-untranslated region (UTR) followed by $609 \mathrm{bp}$ of the coding region and $180 \mathrm{bp}$ of the $3^{\prime}$-UTR according to GenBank acc. no. DQ333202. An assignment of the CDNA to the porcine genome sequence revealed the boundaries between exons and introns of the $p C 8 G$ following the intron-exon junction rule (Figure 1). The deduced protein sequence covers 202 amino acids (GenBank acc. no. 
ABD13970) corresponding to the coding region of the cDNA sequence. The first 20 amino acids represented for the typical feature of the signal peptide (The SignalP 3.0 Server - http:// www.cbs.dtu.dk/services/SignalP-3.0, Bendtsen et al. 2004). Thus, the predicted mature pC8G contains 182 amino acids (approximately $20.29 \mathrm{kDa}$ ) covering three cysteine residues. The $p C 8 G$ cDNA ( $\geq 65 \%$ ) and protein ( $\geq 71 \%$ ) sequence show a moderate to high degree of identity with mouse, rabbit, dog and human sequences. A fragment, which is similar to the lipocalin module, was detected between amino acids 28 and 164 (the Conserved Domains Search CDS/CCD, http://www.ncbi.nlm.nih.gov/Structure/cdd/wrpsb.cgi). A phylogenic tree was constructed to display the evolutionary relationship between the protein sequences of C8G in various species and porcine lipocalin proteins (Figure 2).

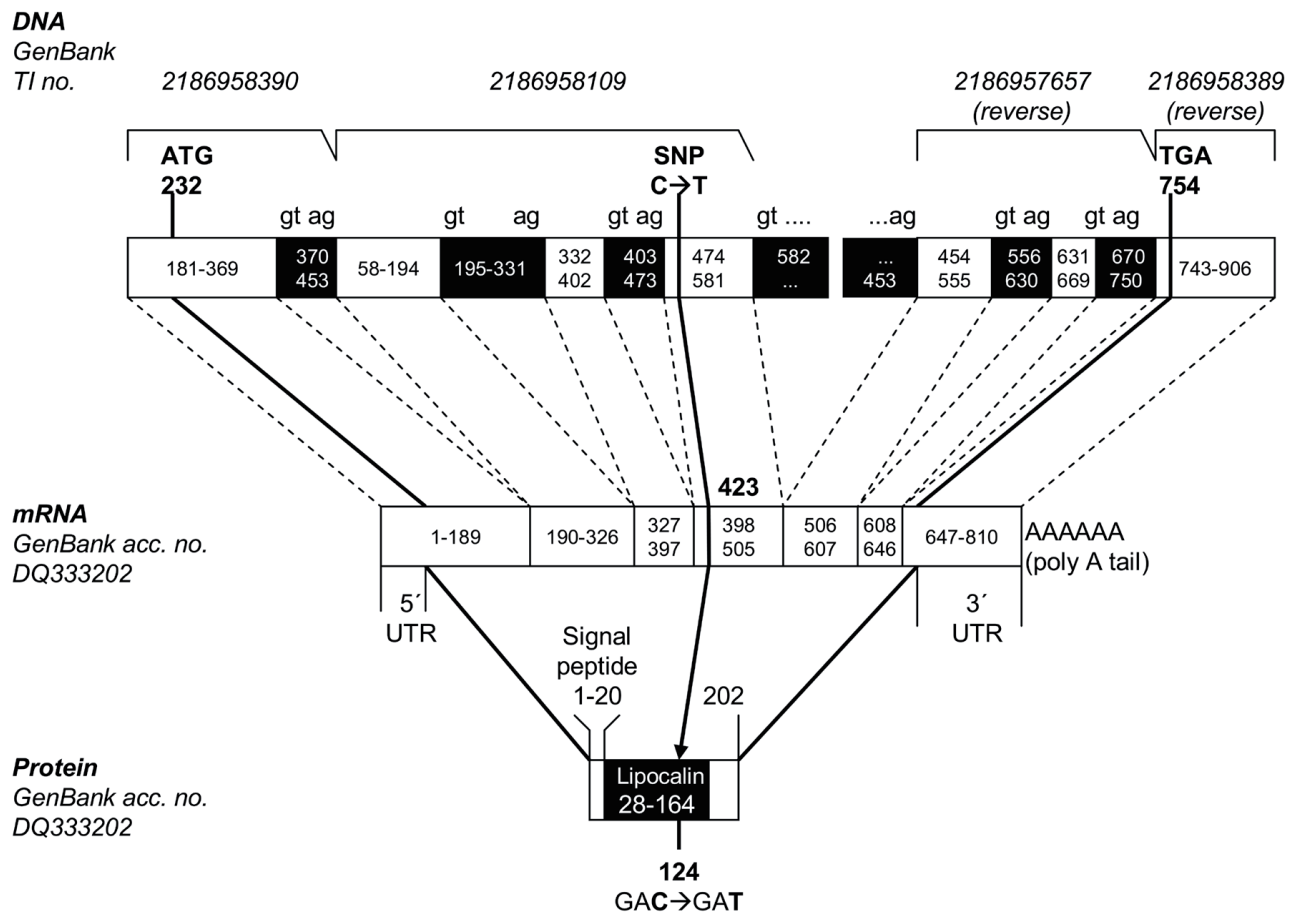

Figure 1

Outline of $p$ C8G CDNA and protein structure compared to the porcine genomic DNA (GenBank acc. no. AK233484)

By comparative sequencing of cDNA fragments of different individuals, a synonymous SNP was found at nt 423 of DQ333202 (SNP c.423C>T; codon 124GAC $\rightarrow$ GAT) within the coding region of the C8G. The SNP was confirmed and subsequently genotyped by PCR-RFLP using the enzyme Psyl. The SNP does not segregate among the European commercial breeds of German Landrace (LR) and Pietrain (PI) as revealed by genotyping 30 unrelated individuals. In the Vietnamese autochthonous breed Muong Khuong (MK) the allele »T« - that is fixed in LR and PI - was found with a frequency of $10 \%$. Genotypic and allelic frequencies fit to HardyWeinberg equilibrium in the MK population (Table 2). 


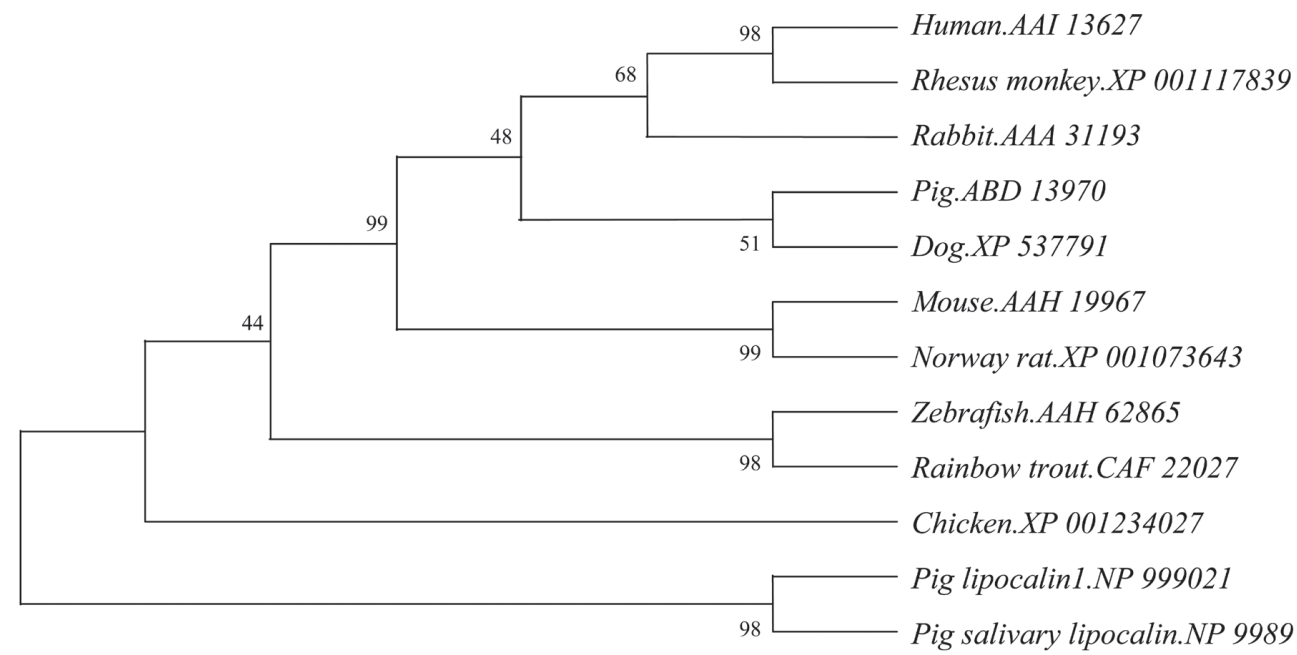

Figure 2

Phylogenic tree among C8G protein sequences of several species and porcine lipocalin 1 and salivary lipocalin constructed using the MEGA3 tool (Kumar et al. 2004). Numbers at the branches are confidence values based on Felsenstein's bootstrap.

According to RH mapping $p$ C8G was assigned to chromosome 1q2.13 (most significantly linked marker: $\mathrm{SSC10D} 08$ with distance in $\mathrm{CR}=44, \mathrm{LOD}$ score $=8.26$, retention frequency $=0.15$ ) corresponding to position 313.759 .193 to 313.757 .973 on SSC1 (Sus scrofa built 10.2). This chromosome region also contains $L C N 1$, another member of the lipocalin family (Čepica et al. 1999).

Table 2

Genotypic and allelic frequencies in several pig populations

\begin{tabular}{lrrrrrr}
\hline & LR & $\%$ & PI & $\%$ & MK & $\%$ \\
\hline Genotype (n) & 30 & & 30 & & 25 & \\
CC & 0 & 0.00 & 0 & 0.00 & 21 & 0.84 \\
CT & 0 & 0.00 & 0 & 0.00 & 3 & 0.12 \\
TT & 30 & 1.00 & 30 & 1.00 & 1 & 0.04 \\
Allele & & & & & & \\
C & 0 & 0.00 & 0 & 0.00 & 45 & 0.90 \\
T & 60 & 1.00 & 60 & 1.00 & 5 & 0.10 \\
\hline
\end{tabular}

Estimates of least square means of hemolytic complement activity according to the interaction of time $\times$ genotype revealed an increment of alternative haemolytic complement activity (AH50) throughout the experiment from week 6 to week 16 of age. Classical haemolytic complement activity ( $\mathrm{CH} 50)$ increased from before the first Mycoplasma hyopneumoniae inoculation (MHO) and peaked at Aujeszky Virus inoculation measurement at day 4 (ADV4). The increments immediately after the respective vaccinations represent an acute response to the immunological stimulation, whereas the slope between the three series of blood takings associated with the vaccinations are due to aging and reflect continuous improvement of the immune responsiveness wherein both specific antibody generated after each inoculation and unspecific antibody accumulated along the experiment (Figure 3). 

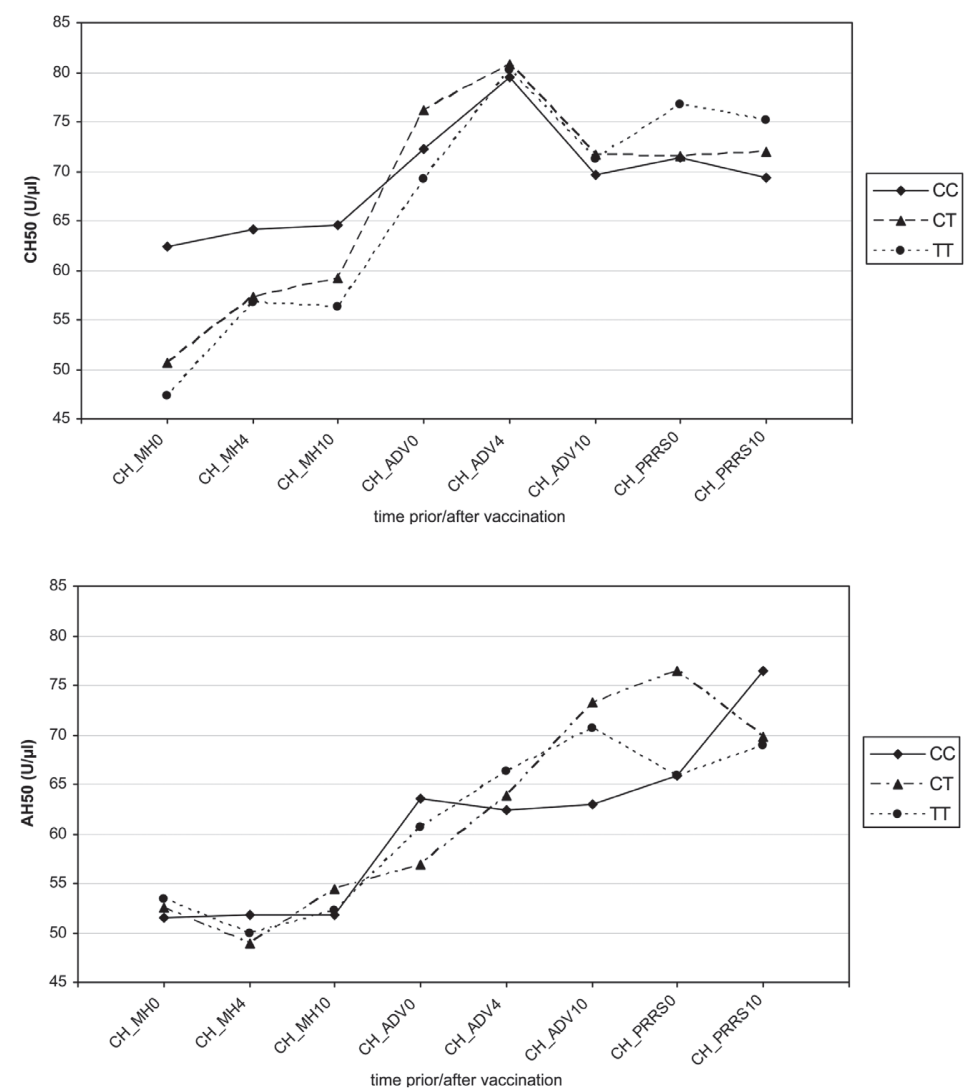

Figure 3

Plots of least square means of haemolytic complement activity in the classical (CH50) and alternative (AH50) pathway for the interaction time $\times$ genotype

The progress of complement activity was similar for all three genotypes. The most prominent differences occurred at late time points in the experiment. In fact, application of FBAT indicate an association of $\mathrm{C} 8 \mathrm{G}$ with $\mathrm{AH} 50$ and $\mathrm{CH} 50$ at 16 weeks of age immediately before the PRRS vaccination (AH50_PRRS0, $P=0.087$; $C H 50 \_P R R S 0, P=0.027$ ). However, the results did not indicate a consistent effect of the respective alleles on haemolytic complement activity in the alternative and the classical pathway. Interestingly, the allele »C « was highly frequent in MK animals. Obviously, the Vietnamese potbelly pigs contributed this allele to $F_{2}$ DUMI animals (Duroc $\times$ BMP) because the BMP was bred from Vietnamese potbelly pig, Saddleback pig and German Landrace (Hardge et al. 1999). Moreover, the MK pig is known as a breed which is able to resist diseases and endoparasites and adapt well to harsh environmental conditions (temperature, humidity, nutrition, management) - though not yet scientifically verified and represents a naturally selected population. In this sense MK, like other Vietnamese local breeds, is a potential source for promising alleles of unpredictable economic value (Lemke et al. 2005).

The C8G binds to C8A to form a stable C8A-G complex depending on the interchain disulphide bonds. Both genes are located on different chromosomes (porcine C8G on SSC1; porcine C8A on SSC6) (Nakajima et al. 1998, Đỗ et al. 2011). Correspondingly, C8A and C8G are synthesised independently and must associate co- or posttranslational before disulphide bond formation can occur (Schreck et al. 2000). Comparative sequencing revealed no SNPs 
causing changes in the amino acid sequence. Thus any potential polymorphism linked to the SNP c.423C>T that might have effects on the haemolytic complement activity can be expected to affect the expression of C8G. It is possible that C8G does not directly affect the haemolytic complement activity but it either acts in other mechanisms or interacts to other components of the immune system to support immune defence. Several evidences indicate that C8G may act as a retinol transporting protein in plasma (Haefliger et al. 1991). Interestingly, C8G is not absolutely required for expression of C8 haemolytic activity and for binding of $\mathrm{C} 8$ to either $\mathrm{C} 5 \mathrm{~b}-7$ or $\mathrm{C} 9$. However, addition of recombinant $\mathrm{C} 8 \mathrm{G}$ to the $\mathrm{C} 8 \mathrm{~A}-\mathrm{C} 8 \mathrm{~B}$ complex increases its haemolytic activity. Therefore, it is suggested that C8G may not be required for lysis but it does enhance MAC activity (Schreck et al. 1998, 2000).

Our data provide weak evidence for the association of the SNP $c .423 \mathrm{C}>\mathrm{T}$ detected in the porcine C8G with complement activity and thus promotes further studies of pC8G as a candidate gene for innate immune response and disease resistance.

\section{Acknowledgement}

This study was supported by the BMBF/DLR (Federal Ministry of Education and Research $(\mathrm{BMBF}) /$ International Bureau, Project Management Agency of the German Aerospace Center (DLR); Project-No: VNB 03/B01).

\section{References}

Alper CA, Marcus D, Raum D, Petersen BH, Spira TJ (1983) Genetic polymorphism in C8 beta-chains. Evidence for two unlinked genetic loci for the eighth component of human complement (C8). J Clin Invest 72, 1526-1531

Bendtsen JD, Nielsen H, von Heijne G, Brunak S (2004) Improved prediction of signal peptides: SignalP 3.0. J Mol Biol 340, 783-795

Čepica S, Yerle M, Stratil A, Schroeffel J, Redl B (1999) Regional localization of porcine myod1, myf5, lep, ucp3 and LCN1 genes. Anim Genet 30, 462-478

Dewald G, Cichon S, Bryant SP, Hemmer S, Noethen MM, Spurr NK (1996) The human complement C8G gene, a member of the lipocalin gene family: polymorphisms and mapping to chromosome 9q34.3. Ann Hum Genet 60, 281-291

Do VAK Ponsuksili S, Muráni E, Wimmers K (2011) Polymorphic sites in the $5^{\prime}$-region of the porcine C8A gene. Arch Tierz 54, 430-438

Flo TH, Smith KD, Sato S, Rodriguez DJ, Holmes MA, Strong RK, Akira S, Aderem A (2004) Lipocalin 2 mediates an innate immune response to bacterial infection by sequestrating iron. Nature 432, 917-921

Haefliger JA, Peitsch MC, Jenne DE, Tschopp J (1991) Structural and functional characterization of complement C8y, a member of the lipocalin protein family. Mol Immunol 28, 123-131

Hardge T, Koepke K, Reissman M, Wimmers K (1999) Maternal influences on litter size and growth in reciprocal crossed Miniature Pigs and Durocs. Arch Tierz 42, 83-92

Hawken RJ, Murtaugh J, Flickinger GH, Yerle M, Robic A, Milan D, Gellin J, Beattie CW, Schook LB, Alexander LJ (1999) A first-generation porcine whole-genome radiation hybrid map. Mamm Genome 10, 824-830

Horvath S, Xu X, Laird NM (2001) The family based association test method: strategies for studying general genotype-phenotype associations. Eur J Hum Genet 9, 301-306

Kumar S, Tamura K, Nei M (2004) MEGA3: Integrated software for molecular evolutionary genetics analysis and sequence alignment. Brief Bioinform 5, 150-163 
Laird N, Horvath S, Xu X (2000) Implementing a unified approach to family based tests of association. Genet Epidemiol 19, S36-S42

Lemke U, Huyen LTT, Roeßler R, Thuy LT, Valle Zárate A (2005) Impact of the use of exotic compared to local pig breeds on socio-economic development and biodiversity in Vietnam. Conference on International Agricultural Research for Development. Stuttgart-Hohenheim, October 11-13, 1-4

Milan D, Hawken R, Cabau C, Leroux S, Genet C, Lahbib Y, Tosser G, Robic A, Hatey F, Alexander L, Beattie C, Schook L, Yerle M, Gellin J (2000) IMpRH server: an RH mapping server available on the Web. Bioinformatics $16,558-559$

Nakajima E, Itoh T, Suzuki K, Kawakami K, Takeda K, Onishi A, Komatsu M (1998) Characterization, chromosomal localization, and genetic variation of the alpha subunit of porcine eighth component of complement. Anim Genet 29, 377-380

Plumb ME, Scibek JJ, Barber TD, Dunlap RJ, Platteborze PL, Sodetz JM (1999) Chimeric and truncated forms of human complement protein $\mathrm{C} 8$ alpha reveal binding sites for $\mathrm{C} 8$ beta and $\mathrm{C} 8$ gamma within the membrane attack complex/perforin region. Biochemistry 38, 8478-8484

Rozen S, Skaletsky HJ (2000) Primer3 on the WWW for general users and for biologist programmers. In: Krawetz S, Misener S (eds.) Bioinformatics Methods and Protocols: Methods in Molecular Biology. Humana Press, Totowa, NJ, USA, 365-386

Schreck SF, Parker C, Plumb ME, Sodetz JM (2000) Human complement protein C8 gamma. Biochim Biophys Acta 1482, 199-208

Schreck SF, Plumb ME, Platteborze PL, Kaufman KM, Michelotti GM, Letson CS, Sodetz JM (1998) Expression and characterization of recombinant subunits of human complement component C8: further analysis of the function of C8a and C 8 . J Immunol 161, 311-318

Wimmers K, Lipperheide C, Ponsuksili S, Schmoll F, Hardge T, Petersen B, Schellander K (1999) Haemolytic complement activity and C 3 c serum concentration in pigs. Arch Tierz 42, 93-102

Wimmers K, Mekchay S, Schellander K, Ponsuksili S (2003) Molecular characterization of the pig C3 gene and its association with complement activity. Immunogenetics 54, 714-724

Yerle M, Pinton P, Robic A, Alfonso A, Palvadeau Y, Delcros C, Hawken R, Alexander L, Beattie C, Schook L, Milan D, Gellin J (1998) Construction of a whole genome radiation hybrid panel for high-resolution gene mapping in pigs. Cytogenet Cell Genet 82, 182-188

Received 3 January 2012, accepted 4 April 2012.

Corresponding author:

Ronald M. Brunner

email: brunner@fbn-dummerstorf.de

Leibniz Institute for Farm Animal Biology (FBN), Wilhelm-Stahl-Allee 2, 18196 Dummerstorf, Germany 